\title{
The Status of Malaria among Pregnant Women: A Study in Lagos, Nigeria
}

\author{
Omolade O Okwa
}

\begin{abstract}
A study was carried out on the status of malaria among 800 randomly selected pregnant women in Lagos State, Nigeria. Blood samples were obtained from finger pricking and tested for malaria parasites in thin blood films and $60 \%$ prevalence of malaria parasites was obtained. Interviews were conducted and structured questionnaires were administered to the pregnant women to obtain information on the clinical and social aspects of malaria. Results show that primigravidae accounted for a greater part of the $60 \%$ prevalence of malaria that affected mainly women in their 1 st to 3 rd month of pregnancy. The ages of the infected women ranged from 30 to 39 years $(77 \%)$. Women with blood groups $\mathrm{A}$ and $\mathrm{O}$ had the highest prevalence of malaria, but there was no statistically significant difference between them and the uninfected women. Women with genotype AA had the highest prevalence of malaria, while pregnant women in Ikeja division had the highest incidence of malaria $(41.7 \%)$. Majority of the infected women believed that mosquito bites and stress were responsible for their infection. Only $21.8 \%$ of the women did not associate mosquitoes with malaria. All the women were familiar with the symptoms of malaria but did not see it as a serious disease that could lead to death. Most of the women used bed nets but not the impregnated brands. There is need to educate women, especially during antenatal visits, on the severity of malaria and the risk of their susceptibility to it during pregnancy. (Afr J Reprod Health 2003; 7[3]: 77-83)
\end{abstract}

\section{RÉSUMÉ}

Le statut du paludisme chez les femmes enceintes: une étude effectuée à Lagos, Nigéria. Nous avons mené une étude sur le statut du paludisme chez 800 femmes enceintes dans l'Etat de Lagos qui ont été selectionnées au hasard. Dés échantillons du sang ont été prélevés à travers la figure de droigt et ont été analysés pour déterminer la présence des parasites du paludisme dans de frottis de sang fluide. Nous avons obtenu $60 \%$ de la prévalence des parasites du paludisme. Des interviews ont été organisées et nous avons administré des questionnaires structurés auprès des femmes enceintes pour obtenir des renseignements sur des aspects cliniques et sociaux du paludisme. Les résultats ont montré qu'une plus grande partie de la $60 \%$ de prévalence du paludsme qui a atteint surtout les femmes entre le premier et le troisieme mois de grossesse étaient des primigravidae. La plus haute prévalence du paludisme était trouvée chez les femmes qui appartenaient aux groupes sanguins A et $\mathrm{O}$, mais il n'y avait pas de différence importante du point de vue statistiques entre elles et les femmes qui n'ont pas été atteintes. Les femmes qui avaient le génotype AA avaient la plus haute prévalence alors que les femmes de la région d'Ikeja avaient la plus haute prévalence du paludisme $(41,7 \%)$. La majorité des femmes atteintes ont cru que la piqure par les moustiques et le stress en étaient responsables de leur infection. Seules $21.8 \%$ des femmes qui n’ont pas lié les moustiques au paludisme. Toutes les femmes connaissaient bien les symptômes du paludisme mais ne le voyaient pas comme une maladie qui pouvaient mener à la mort. La plupart des femmes se servaient des moustiquaires mais pas de types inprégnés. Il y a lieu de renseigner les femmes, surtout pendant les visites à la consultation prénatale, sur la sévérité du paludisme et le risque de leur susceptibilité pendant la grossesse. (Rev Afr Santé Reprod 2003; 7[3]: 77-83)

KeY Words: Malaria, Lagos, Nigeria, pregnant women

Department of Zoology, Parasitology Unit, Lagos State University, P.M.B 1087, Apapa, Lagos State, Nigeria. 


\section{Introduction}

Human malaria is caused by the protozoan parasite of the genus Plasmodium. It lives in the red blood cells and is transmitted by the female anopheles mosquito. Malaria is a disease with major health problems that has attracted global concern, hence, it is regarded as the most important of parasitic diseases. ${ }^{1}$ It is a household name in Nigeria. In Nigeria, like in other endemic areas, its severe and complicated effects are most common among infants and pregnant women. ${ }^{2,3}$

Pregnancy exacerbates malaria through a nonspecific hormone-dependent depression of the immune system. The protective antiplasmodial activity is suppressed at pregnancy, which has clinical consequences with important public health implications on pregnant women. ${ }^{4}$ Malaria infection leads to increased morbidity and mortality and the delivery of premature infants with low birth weights due to intrauterine growth retardation (IUGR) that may have been as a result of placental parasitisation. ${ }^{5}$ Malaria infection is significant in Africa where its fatality as a result of virulent Plasmodium falciparium is a far greater problem than in most parts of the world. ${ }^{6}$

Pregnant women should be adequately informed on how to recognise the symptoms of malaria in their body especially during pregnancy, which is a critical period for women. Studies in West Africa have shown that the persistent failure of some intervention methods in health care delivery has been attributed to complete reliance on only clinical and laboratory diagnosis methods. ${ }^{7}$

This study was therefore conducted to examine the clinical status of malaria, i.e., the prevalence and health factors affecting prevalence among selected pregnant women in Lagos, Nigeria. It also identified some socio-cultural factors like knowledge, attitudes and practices, which are essential factors that can be included in the education of pregnant women for effective control programmes.

\section{Methodology}

Study Area

Lagos is the smallest state and former capital city of Nigeria. It is densely populated. Twenty two per cent of the 787 square miles of the state is made up of lagoons and creeks. It stretches over $180 \mathrm{~km}$ along the coast of the Atlantic Ocean. It extends westward to Badagry and eastwards to Epe, terminating in the riverine area of Lekki. Lagos is a socio-cultural melting point attracting both Nigerians and nonNigerians alike, because of its economic and sociopolitical importance. This has led to migration from the rural areas within the country to the city, hence the diversified ethnic composition of inhabitants of the state. The indigenes of Lagos are mostly Aworis, Eguns and Ijebus. There were four administrative divisions in the state until 1984, namely, Ikeja, Epe/ Ikorodu, Badagry and Lagos. These five divisions were therefore used for the purpose of this study to enhance easy analysis of data.

\section{Field Setting}

The following government hospitals were used for the study:

- Ikeja: Lagos State University College of Medicine (LASUCOM) and Lagos University Teaching Hospital (LUTH)

- Epe/Ikorodu: General Hospital, Epe, and General Hospital, Ikorodu

- Badagry: General Hospital, Badagry, and Badagry Maternity Hospital

- Lagos: General Hospital, Lagos, and Lagos Island Maternity Hospital

\section{Case Selection}

Random sampling technique was used to select 800 women who were on antenatal visits. Two hundred were chosen from each division and 100 from each hospital. The women were selected based on their ability to respond to the questions, i.e., knowledge of their blood groups and their genotype. They were all literate and outpatients, residing permanently in their respective divisions. They were all on preventive antimalarial drugs in the current pregnancy.

\section{Parasitological Diagnosis of Malaria}

Blood samples were obtained from the sampled women using finger pricking method after securing informed consent from them and the hospital authorities. The samples were placed on labelled slides and tested for malaria parasites using Giemsa 
stains. Diagnosis was carried out by a medical laboratory technologist within a period of four weeks (February 1999). The blood groups and genotype of the women were also confirmed.

\section{Administration of Questionnaire}

A structured questionnaire was used to elicit information from the women after it had been validated by removing irrelevant questions. A pilot study was carried out and pre-tested among ten pregnant women. This helped to restructure and evaluate the effectiveness of the questionnaire. The questionnaire obtained information on clinical status, age and number of pregnancies, incidence of malaria, sociocultural aspects such as knowledge and perception of the disease including symptoms, causes, severity and measures taken to prevent and control it. The questionnaire was administered and recovered within a period of two months (February-March 1999). Open-ended personal interviews were held at the hospitals before the questionnaire was administered to respondents. The interview ascertained certain aspects of the investigation that can best be studied interactively such as the socio-cultural factors associated with malaria. It gave opportunity for better dialogue between author and respondents, which made it possible to ask questions that could not be included in the questionnaire and extract well defined answers to certain questions. An average of 10 minutes was used to interview each respondent.

\section{Statistical Analysis}

Chi-square method was used to determine differences in results between infected and uninfected pregnant women $(\mathrm{p}<0.05$ was significant and $\mathrm{p}>$ 0.05 was non-significant).

\section{Results}

\section{Clinical Characteristics}

Table 1 shows the clinical characteristics of the selected 800 pregnant women in Lagos State, Nigeria.

\section{Diagnosis of Malaria Parasites}

Laboratory test for malaria parasites in respondents' blood samples indicated $480(60 \%)$ positive results and $320(40 \%)$ negative... Out of the 480 women diagnosed as having malaria, 302 (62.9\%) were primigravidae. The infected women were mainly in the first trimester of pregnancy while the uninfected were mainly in the third trimester of pregnancy.

\section{Genetic Factors}

Most of the women were in blood groups A and O. Women with genotype AA had the highest incidence of malaria, $262(54.6 \%)$, while most of the uninfected women had genotype AS, 241 (75.3\%).

Drug Use

One hundred and thirty five (28.1\%) of the infected women used chloroquine for malaria. Others used halfan, pyrimethamine, fansidar, nivaquine and maloxine, in decreasing order. Among the uninfected pregnant women, chloroquine also had the highest use, 120 (37.5\%). Nivaquine, local remedies, halfan, fansidar and pyrimethamine were also used in decreasing order.

\section{Socio-Cultural Characteristics}

Table 2 shows the socio-cultural characteristics of the selected 800 pregnant women. One hundred and fifty three $(31.9 \%)$ of infected pregnant women resided in Ikeja, followed by Epe/Ikorodu (107 or $22.3 \%$, while women who resided in Lagos Island were least infected. Most of them were between 30 and 39 years old. Within this age group, 370 (77\%) were infected and 109 (59.1\%) were uninfected. Majority of the women were Christians; 363 (75.6\%) of infected and $259(80.9 \%)$ of the uninfected pregnant women were Christians.

The women's knowledge and perception of malaria was encouraging, as $200(41.7 \%)$ of infected women mentioned mosquito bites and stress as factors that may lead to malaria infection. Other causes mentioned in addition to mosquito bites were underfeeding and humid environment. Only 7 $(2.18 \%)$ of the uninfected pregnant women did not mention mosquito bites as a cause of malaria. The symptoms associated with malaria, according to the women, were headache, chills, loss of appetite and ody temperature. 
Table 1 Clinical Characteristics of Pregnant Women in Lagos State $(\mathbf{N}=\mathbf{8 0 0})$

\begin{tabular}{|c|c|c|c|c|}
\hline & Infected & $\%$ & Uninfected & $\%$ \\
\hline Clinical status & 480 & 60.0 & 320 & 40.0 \\
\hline \multicolumn{5}{|c|}{ Number of pregnancies $(p<0.05, d f=3)$} \\
\hline 1 & 302 & 62.9 & 80 & 25.0 \\
\hline 2 & 98 & 20.4 & 150 & 46.9 \\
\hline 3 & 44 & 9.1 & 46 & 14.3 \\
\hline$>4$ & 36 & 7.5 & 44 & 13.7 \\
\hline \multicolumn{5}{|c|}{ Age of pregnancy in months $(p<0.05, d f=3)$} \\
\hline $1-3$ & 208 & 43.3 & 100 & 31.2 \\
\hline $3-5$ & 72 & 15.0 & 79 & 24.7 \\
\hline $5-7$ & 195 & 40.6 & 16 & 5.0 \\
\hline$>7$ & 5 & 1.0 & 125 & 39.1 \\
\hline \multicolumn{5}{|c|}{ Blood group $(p<0.05, d f=3)$} \\
\hline $\mathrm{A}$ & 132 & 27.5 & 100 & 31.2 \\
\hline $\mathrm{B}$ & 110 & 22.9 & 50 & 15.6 \\
\hline $\mathrm{AB}$ & 106 & 22.1 & 52 & 16.2 \\
\hline $\mathrm{O}$ & 132 & 27.5 & 118 & 36.9 \\
\hline \multicolumn{5}{|c|}{ Genotype $(p<0.05, d f=2)$} \\
\hline AA & 262 & 54.6 & 70 & 21.9 \\
\hline AS & 200 & 4.7 & 241 & 75.3 \\
\hline SS & 18 & 3.7 & 9 & 0.2 \\
\hline \multicolumn{5}{|c|}{ Drugs in use $(p<0.05, d f=7)$} \\
\hline Halfan & 65 & 13.5 & 35 & 10.9 \\
\hline Chloroquine & 135 & 28.1 & 120 & 37.5 \\
\hline Maloxine & 30 & 6.25 & 10 & 3.1 \\
\hline Fansidar & 51 & 10.2 & 25 & 7.8 \\
\hline Nivaquine & 50 & 10.4 & 59 & 18.4 \\
\hline Pyrimethamine & 55 & 11.5 & 20 & 6.2 \\
\hline Local remedies & 80 & 16.7 & 41 & 2.8 \\
\hline None & 14 & 2.9 & 10 & 3.1 \\
\hline
\end{tabular}

Only 180 (37.5\%) infected and 100 (31.25\%) uninfected pregnant women opined that malaria is a serious problem. Only $20(4.17 \%)$ infected and 35 $(10.9 \%)$ uninfected pregnant women believed that malaria could be fatal. Most of the infected women
(283 or $58.9 \%$ ) mentioned the use of bed nets as the best measure to be taken to prevent malaria infection, while uninfected women mostly (124 or $38.7 \%$ ) mentioned the elimination of breeding sites as the best preventive measure. 
Table 2 Socio-Cultural Parameters of Pregnant Women in Lagos State $(\mathbf{N}=\mathbf{8 0 0})$

\begin{tabular}{|c|c|c|c|c|}
\hline & Infected & $\%$ & Uninfected & $\%$ \\
\hline \multicolumn{5}{|l|}{ Place of residence $(p<0.05, d f=3)$} \\
\hline Ikeja & 153 & 31.9 & 47 & 14.7 \\
\hline Epe/Ikorodu & 107 & 22.3 & 93 & 29.1 \\
\hline Ojo/Badagry & 128 & 26.7 & 72 & 22.5 \\
\hline Lagos Island & 92 & 19.2 & 108 & 33.7 \\
\hline \multicolumn{5}{|l|}{ Age (years) $(p<0.05, d f=3)$} \\
\hline$<20$ & 10 & 2.1 & 5 & 1.0 \\
\hline $20-29$ & 95 & 19.8 & 123 & 38.4 \\
\hline $30-39$ & 370 & 77.1 & 189 & 59.1 \\
\hline$=40$ & 5 & 1.0 & 3 & 0.9 \\
\hline \multicolumn{5}{|l|}{ Cause of malaria $(p<0.05, d f=5)$} \\
\hline Mosquito bite & 90 & 18.7 & 120 & 37.5 \\
\hline Mosquito bite/stress & 200 & 41.7 & 80 & 25.0 \\
\hline Mosquito bite/humid environ. & 80 & 16.7 & 40 & 12.5 \\
\hline Mosquito bite/underfeeding & 110 & 22.9 & 60 & 18.7 \\
\hline All of the above & 0 & 0.0 & 13 & 4.0 \\
\hline None of the above & 0 & 0.0 & 7 & 2.1 \\
\hline \multicolumn{5}{|l|}{ Religion $(p<0.05, d f=2)$} \\
\hline Islam & 108 & 22.5 & 56 & 17.5 \\
\hline Christianity & 363 & 75.6 & 259 & 80.9 \\
\hline Others & 9 & 1.8 & 5 & 1.56 \\
\hline \multicolumn{5}{|l|}{ Symptom $(p<0.05, d f=4)$} \\
\hline Headache & 100 & 20.8 & 73 & 22.8 \\
\hline High body temperature & 75 & 15.6 & 35 & 10.9 \\
\hline Loss of appetite & 50 & 10.4 & 22 & 6.8 \\
\hline Fever/chills & 50 & 6.2 & 16 & 5.0 \\
\hline All of the above & 225 & 46.9 & 174 & 54.4 \\
\hline \multicolumn{5}{|c|}{ Is malaria a serious disease? $(\phi<0.05, d f=1)$} \\
\hline Yes & 180 & 37.5 & 100 & 31.2 \\
\hline No & 300 & 62.5 & 202 & 63.1 \\
\hline \multicolumn{5}{|c|}{ Is malaria a fatal disease? $(p<0.05, d f=1)$} \\
\hline Yes & 20 & 4.1 & 35 & 10.9 \\
\hline No & 460 & 95.8 & 285 & 89.1 \\
\hline \multicolumn{5}{|c|}{ What measure can you take to avoid mosquitoes? $(p<0.05, d f=7)$} \\
\hline Use bed nets & 283 & 58.9 & 108 & 33.7 \\
\hline Screen doors/widows & 97 & 20.2 & 56 & 17.5 \\
\hline Use mosquito repellants & 52 & 10.8 & 32 & 10.0 \\
\hline Eliminate breeding sites & 48 & 10.0 & 124 & 38.7 \\
\hline
\end{tabular}




\section{Discussion}

According to Matteeli et $\mathrm{al}^{4}$ and Brabin, ${ }^{9}$ the primigravidae are more susceptible to malaria infection than the multigravidae, which is also supported by this study. The multigravidae are presumably less affected because immunological memory from first pregnancy is retained. In first and second pregnancies women are especially vulnerable. Mcgregor ${ }^{10}$ identified the factors responsible for susceptibility of primigravidae to malaria as inhibition of type 1 cytokine responses (interferon, interleukins 2 and 12 and TNF). Exchange of maternal and fetal substances mainly occur at the placenta, thus, placenta parasitisation by the erythrocytes may influence the risk of death, induce low birth weight resulting from IUGR, premature delivery, or both. A consensus that IUGR is the predominant mechanism was confirmed by Stekeetee et al. ${ }^{5}$

One of the surprising findings in this study was that most pregnant women did not complain of acute symptoms of malaria but tested positive when diagnosed. Some of the women with symptoms were not diagnosed as positive for malaria parasites. The symptoms of malaria overlap with other infections like typhoid fever, pneumonia, etc, therefore, proper diagnosis should always be carried out. This finding is similar to that of Brabin, 3,9 who suggested that malaria infection is highly controlled by the immune system and as such may be clinically unrecognised unless diagnosed, making pregnant women to be particularly at risk.

The high prevalence of malaria parasites can be attributed to the fact that Lagos State is a good environment for mosquito breeding especially during the rainy season when there is high peak transmission. Mosquitoes require still water to breed and as such the habits of anopheles mosquitoes determine the geographic pattern of disease. Ikeja division had the highest number of infected pregnant women, which is a result of the high frequency of stagnant pools and blocked drainages in this division.

Pregnant women appear to be at greater risk in their first three months of pregnancy. According to Brabin, ${ }^{3}$ in areas where malaria is endemic, pregnant women have frequent episodes of malaria from early to mid pregnancies. Thus, pregnant women should be given antimalarial drugs at their first antenatal visit whether or not they show symptoms. This should take place early in pregnancy, as this is an important period of fetal growth. If delayed until later in pregnancy, the effect on the mother and child may be disastrous.

According to Brabin, ${ }^{9}$ retardation of fetal growth with resulting low birth weight mainly affects babies born from first pregnancies. In some endemic areas, as many as $40 \%$ of babies from first pregnancies had low birth weight because their mothers had malaria. At pregnancy, immunity has been altered; hence, with malaria $70-80 \%$ of pregnant women in malarious areas are susceptible to anaemia. ${ }^{11}$

Older women aged 30-39 years also appeared to be more susceptible to malaria parasitaemia than younger women. This result contradicts findings from most previous works and may be due to sampling errors. Most of the women in this study coincidentally consist of this age group. Also, the population sampled were literate women; $90 \%$ had tertiary education. Women tend to delay marriage nowadays because of the desire to acquire education and have a source of income before marriage. Women now want to attain equal status with men. The declining economic situation and increasing unemployment in Nigeria also affects family life in the country.

Women in blood groups A and $\mathrm{O}$ appear to be very susceptible to malaria. Women with genotype A had the highest occurrence of malaria. Resistance to malaria has been found to be associated with certain genetic factors. The haemoglobin $\mathrm{S}$ is known to interfere with the growth and retardation of Plasmodium falciparium. SS patients are therefore very resistant, but in this study 18 pregnant women were SS and nine of them had malaria. None of them was up to 30 years. According to Hills, ${ }^{2}$ people who are homozygous SS are usually not viable, so they die before 30 years of age, while the AS survive and take protection conferred on them by this trait. Hence, individuals with AA are more susceptible to malaria because their red blood cells are conducive for the growth and development of $P$. falciparium. The infected pregnant women with genotype SS, therefore, need special care because they are already anaemic. $^{13,14}$ 
Despite the use of antimalarials among these women they still tested positive. Irrational use of malaria drugs with under-dosage and sub-curative measurements using substandard and fake drugs has been identified as a major cause of drug resistance in malaria parasites. ${ }^{15,16}$ Salako ${ }^{15}$ reported that when a patient fails to respond to a drug and diagnosis has been confirmed by blood test, an alternative drug could be used. Antimalarials need to be taken with unfailing regularity. Side effects like itching could lead to discontinuation of drug and the bitter taste of drugs could induce vomiting of the drug in some cases. Good quality malaria drugs obtained from reputable pharmacies should be used and the recommended dosage taken.

The women were conversant with the symptoms of malaria. Mosquitoes were very well known. They are the best known of all insects because of their aggressiveness, constituting a biting nuisance. They are called efon or yanmuyanmu by the Yoruba and antanwu by Igbo. The larvae are also well known and called tanwigi. Bed nets were mainly used in preventing humans from mosquito bites. The use of impregnated bed nets that appear to be in vogue was not even mentioned.

The women do not seem to have seen the risk in having malaria during pregnancy. To reduce malaria transmission in the state, the Lagos State Government embarked on Eko Malaria Control Programme, which provides free treatment for malaria patients in government hospitals. At the federal level, the Petroleum Trust Fund (PTF) provides chemoprophylactic drugs to patients at cheap prices, thus enhancing prompt treatment of malaria.

Pregnant women should not tolerate the symptoms of malaria until they are critically ill as is usually the case. Information should be provided by antenatal care units on how to prevent malaria and on the proper use of malaria drugs. Women need to be enlightened on their susceptibility to malaria, as most of them are ignorant that most neonatal deaths and low birth weight babies are as a result of malaria. Special health education directed at pregnant women should be incorporated into malaria enlightenment programmes.

\section{REFERENCES}

1. White JN. Malaria: watch for the symptoms. World Health 1991; Sept.-Oct. 8-9.

2. Warrell DA. Cerebral malaria. Clinical features, pathophysiology and treatment. Ann Trop Med Parasitol 1997; 91: 875-884.

3. Brabin JB. Malaria: Risks during pregnancy. World Health 1991; Sept.-Oct. 26.

4. Matteeli S, Caligras F, Castelli F and Carosi G. The placentae and malaria. Ann Trop Med Parasitol. 1997; 91: 803-810.

5. Stekeetee RW, Wirima JJ, Hightower AW, Slutsker L, Heliman DL and Breman JG. The effect of malaria. Malaria prevention in pregnancy on offspring birthweight, prematurity and intra uterine retardation in rural Malawi. AmerJ Trop Med Hygiene 1996; (Suppl.): 824-832.

6. Molineaux L. Malaria and mortality. Some epidemiological consideration. Ann Trop Med Parasitol. 1997; 91: 811-825.

7. Tropical Disease Research. Malaria. 13th Progress Programme Report. WHO/GENEVA. 1997; 4049.

8. Brabin BJ. An analysis of malaria infections in Africa. Bull World Health Org 1993; 61: 1005-116.

9. Brabin BJ. Epidemiology of infection in pregnancy. Rev Infect Dis 1985; 7: 579-525.

10. McGregor LA. Epidemiology, malaria and pregnancy. Amer J Trop Med Hygiene 1984; 33: $517-$ 525.

11. Beales PF. Anaemia in malaria control. A practical control. Amer J Trop Med Parasitol 1997; 91: 713718.

12. Hills AV. Genetic susceptibility to malaria. Ann Trop Med Parasitol 1996; 112(Suppl.): 573-584.

13. Hoffman SL. Diagnosis, treatment and prevention of malaria. Med Clin N Amer 1992; 76: 1327-1355.

14. Tropical Disease Research. 14th Progress Programme Report, 1998, 29.

15. Salako LA. Malaria. Forms of treatment. World Health 1991; Sept.-Oct. 10-20.

16. Salako LA. Expert warns against the use of antimalarials. Sunday Concord 1992; May 24: 23. 